\title{
Lapurdum
}

Euskal ikerketen aldizkaria | Revue d'études basques |

Revista de estudios vascos | Basque studies review

$11 \mid 2006$

Numéro XI

\section{Testuen historia dela-eta : Duvoisinen literatura iruzurrak eta santa Jenobebaren koplak}

\section{Bernard Oyharçabal}

\section{(2) OpenEdition \\ Journals}

\section{Édition électronique}

URL : http://journals.openedition.org/lapurdum/396

DOI : 10.4000/lapurdum.396

ISSN : 1965-0655

\section{Éditeur}

IKER

\section{Édition imprimée}

Date de publication : 1 novembre 2006

Pagination : 281-290

ISBN : 978-2-86781-474-7

ISSN : $1273-3830$

\section{Référence électronique}

Bernard Oyharçabal, «Testuen historia dela-eta : Duvoisinen literatura iruzurrak eta santa Jenobebaren koplak », Lapurdum [Linean], 11 | 2006, Sarean emana---an 01 avril 2008, kontsultatu 22 avril 2019. URL : http://journals.openedition.org/lapurdum/396; DOI : 10.4000/lapurdum.396 


\title{
Testuen historia dela-eta: Duvoisinen literatura iruzurrak eta santa Jenobebaren koplak
}

\author{
B. OYHARÇABAL \\ (Iker, CNRS)
}

Duela bizpahiru urte Lapurdum IX.ean santa Elisabetez eta lehenbiziko pastoral zaharrez eginikako lan batean, F. Michelek (1854 eta 1857, 47-48. or.) eta Garcia \& Urkizuk (1991, I. liburukia, 46. kantua, 88-89. or.) ezagutarazi santa Jenobeba tragediako kantua aipatu nuen. Adierazten nuen artikulu hartan nire ustez ez zela dudarik iruzur literario baten ondorio zela kantu hura (eta omenkako tragedia hura bera), eta segurenaz ere Duvoisinek artzaintsa xahar baten ahotik bildu zituelako bertso horiek, egiazki, berak bere baitarik osoki asmatu zituela. Geroztik hona ez dut iritzia aldatu; alderantziz. Ordea, duela ez aspaldi Baionako Euskal Erakustokiko eskuizkribuen artean Duvoisinek utzi kaieren miatzen ari nintzen batez, kopla haien eskuzko kopia bat aurkitu baitut, haien berri eman nahi nuke hemen, aitzinetik egin zen Garzia \& Urkizuren (1991) argitalpena [hemendik aitzina G\&U], ezagutzen zen bakarra, puntu batean baino gehiagotan zuzentzekoa dela iruditzen baitzait. Paradaz balia, azkenean, Duvoisinek euskarazko bertso horientzat idatzi zuen frantsesezko itzulpena ere ekarriko dut hona, Michelek $(1854,1857)$ egin zuen hitzez hitzeko itzulpen hertsiari ez baitarraio.

§1. XIX. mendearen erditsuan, Europako beste parteetan bezala, Euskal Herrian ere guztiz loratu ziren literatura herrikoiari buruzko ikerketak. Orduan egin ziren ohiko literaturako lehen bildumak, eta jakintsuak eta idazleak entseiatu ziren urruneko garaietan bizi ziren gizaldien hatsetik, populu xehearen gomendiotan utzirikako hondarkinez baliatuz, zerbaixka bederen biltzera. Iparraldean, F. Michel agertzen da bereziki kultur aldaketa horren aitzindari, eta Le Pays Basque haren liburua, 1857an argitaratua, da aurreko hamarkadetan sortu jakingose berri horren ondorio adierazgarrienetarik bat. Karia horretara aurreko mendean Eskozia lanbrotsuan jadanik gertatu bezala, zenbait iruzur literario egin ziren Euskal Herrian ere, ez eiki Mcphersonenak bezain famatuak, baina halere arrakasta zerbait izan zutenak. Hala gertatu zen, adibidez, zenbait urte lehenago Garay de Montglavek ezagutarazi zuen zenbait kantu epiko apokriforekin, bai eta Chahok ondu zituen beste batzuekin ere bai. Kontu hauen itzulinguruak hurbildik aztertu dizuzte Bladék (1869), Vinsonek (1884) eta berrikiago Juaristik (1987) eta Bidartek (2001), eta ez dut han erranez landa deus berririk gaineratzeko.

Ordea, autore horiek aipatu gabe utzi dituzte testuinguru horretan antzerkigeneroan egin ziren mota bertsuko iruzurrak, franko luzaz seinalatu gabe egon 
direnak (Oyharçabal 2004). Antzerki-lanei dagokienaz aipatzeko den lehen iruzurrezko obra Marie de Navarre izeneko neurtitzezko drama da. Izan ere, 1841eko martxoko Album Pyrénéen deitu agerkarian (89-102 or.), Duvoisinek Poésie dramatique des Basques izenburuko artikulu bat argitaratu zuen, hartan eskuizkribu anonimo batean aurkitu zuen antzerkiaren deskripzioa egiten baitzuen. Antzerki hartan 10. mendearen hondarreko gertakari bat antzestua zen, Abarca Nafarroako erregea eta Marie haren alaba, Abderame Corbovako kalifak preso hartu ondoan gertatua. Duvoisinek bere artikuluan antzerkian kontatu historia xeheki aurkeztu zuen, zenbait pasarte ere emanez, frantsesez, baina ondoan euskarazko jatorrizko bertsioa izanik. Duvoisinek ez zuen testu horretan inon Zuberoako herri teatroa aipatzen, nahiz badirudien haren oihartzuna zekarrela, euskaldunen ohiko antzerkiez hauxe zioelarik:

mais les Basques n'ont jamais lu ces beaux modèles [autore greko, latin eta frantses, handienen antzerkiak]; ils ne se sont formés à aucune école; ils n'ont suivi que leur que leurs propres inspirations; ils n'ont même pas encore de règles fixes : aussi voit-on dans leurs pièces, étincelantes de beautés de tout genre, des défauts que l'étude aurait pu corriger. Les représentations ont lieu, en plein jour, sur un théâtre élevé au milieu de la place publique: on y déploie beaucoup d'appareil et une pompe toute orientale; un concours de monde immense se presse tout autour. Dès que la toile est levée, la musique ouvre l'entrée et désigne, par ses tons, la qualité des personnages qui vont paraître. Ainsi, dans la tragédie Sainte-Hélène, une marche guerrière indique l'entrée des Princes Chrétiens, une musique guerrière celle des Rois Maures; une douce symphonie annonce le Pape. Ordinairement avant chaque scène les Chrétiens, si ce sont eux qui doivent figurer les premiers, et, dans le cas contraire, les Maures exécutent, sur le théâtre, une courte marche au son des instruments. Ces sortes de parades sont fort du goût du peuple. Les brillants costumes et la belle tournure des guerriers, leur marche vive et mesurée le frappent et le préparent à de nouvelles impressions.

Lerro horietan bildua da Duvoisinek 1841eko artikulu hartan, euskaldunen ohiko herri teatroaz zioena. Duda guti da Zuberoako herri teatroaren berri bazekiela orduan Duvoisinek, tradizio hari baitzegozkion ematen zituen xehetasun nagusiak, hala nola Kristau eta Mauroen arteko bereizketa, musikaren baliatzea edo taulen gaineko mugimenduak. Aipu zuen tragediaren gaia ere, santa Helena, ongi ezaguna zen Zuberoako ohiko pastoralen artean ${ }^{1}$. Halere, ez dirudi Duvoisinek bere begiz pastoral errepresentaziorik ikusia zuen orduan (funtsean artikulu hartan horrelakorik ere ez zioen). Besteren erranetarik ari bide zen, beraz, berri horiek ematean. Horrela esplika daiteke zergatik hain guti erran zuen ikusgai horietaz, bizkitartean, urte hartako beste artikulu batean (Duvoisin 1841b) tobera-munstrak aipatzean, bizitasun handiz eta lehen pertsona erabilirik egin zuelarik haien aurkezpena, ikusle izan zela adieraztera emanez ${ }^{2}$.

Duvoisinek erran bezalako Marie de Navarre-ren eskuizkriburik ez da egundaino izan, kontu hori osoki hark berak asmatu baitzuen. Eta gauza ezaguna da aspaldi honetan, gutienetik Hérellek $\left(1926,88-89\right.$. or.) iruzurra argiki azalduz geroztik ${ }^{3}$. Ez 1 - Hain zuzen sujet hori bera zeukan pastorala ikertuko zuen A. Léonek, 1909an argitatu zuen bere tesian.

2 - Halaber horrela uler daiteke nola oihala altxatua da (dès que la toile est levée) bezalako xehetasunik eman zezakeen kanpo teatro aipatzean. Itxura guzien arabera, ez zen ohartu xehetasun hori ez zegokiela baitezpada teatro mota guziei. Dakigun bezala, pastoral ohikoetan, gaurkoetan bezala, ez zen oihal altxatzerik.

3 - A. Léonek $(1909,18$. or.) ere, iruzurrik aipatu gabe, testua fabrikatua izan zela sumatu zuen. 
dugu beraz deus berririk erraten Duvoisinen jokutria hori gogoratzean, iduriz bere garaiko zenbait euskaltzaleri aitortu ere ziena (Hérelle 1926, 89. or.).

$\S 2$. Ordea, ez zen hau izan Duvoisinen iruzur bakarra. Beste bat ere izan zen, dakidanaz, berriki arte (cf. Oyharçabal 2004) seinalatugabea: santa Jenobebaren kantua, azken aldikotz XVIII. mendean emana izan zen antzerki zahar bati omen zegokiona. Duvoisinen lekukotasun batean fidatuz, Michelek (1854, 1857, 47. or.) aipatu zuen lehenbiziko aldiz kantua, Geneviève dans l'oratoire izenburuaren pean, hartarik atera zenbait bertso ohar batean eskainiz eta frantsesezko itzulpen osoa plazaratuz. Michelek ez zuen kantu haren jatorri garbiaz zalantzarik izan, eta haren ondotik aipamen guti izan baitu kantuak euskal estudioetan, haren estatutua ere aldatu gabe egon da, Lapurdiko euskal teatro herrikoiaren hondarkin anonimo gisa kontsideratua izanik.

Iruzurraren aitorpenik, ezta frogabide materialik ere ez da kasu honetan, eta testuen eta euskal teatroaren historiaren eta historiografiaren ikerketek ekarri ninduten lekukotasun gezurrezko bati zegokiola pentsatzera.

XIX. mendearen erdialdean, bere herriko kultura deskubritzen zuen Duvoisin gaztea osoki sinetsirik zegoen euskaldunek iragan aldi urrunetan drama historikoei lotu poesia epiko bat biziarazi zutela. Are gehiago, pentsatzen zuen populu xehean, luzaz, XIX. mendearen atariraino kasik, bizirik iraun zuela poesia hark. Haren ideien berri ematen digute Bladéren (1866) liburua irakurtzean idatzi zituen nota pertsonalek (461 eskuizk., Baionako Hiri Biblioteka, 6.a, 95. or.):

Je doute que les Basques aient écrit des épopées comme il s'en trouve en langue d'oc. S'il en a existé en basque, elles ne sont pas parvenues jusqu'à nous. Mais un fait certain, c'est que nos traditions guerrières ont fait longtemps les délices du peuple dans les spectacles qui se donnaient chaque année, dans une ou plusieurs localités du pays. Les tragédies basques écrites en vers étaient [ezin irakurria] sur les places publiques par les jeunes gens de la commune.

Ohargarri da Duvoisinek garai hartako ikertzaile gehienek bezala ez zuela baitezpada lotzen izan behar izan zuen teatro herrikoi zahar hori garai hartan egiazki Zuberoan egiten ziren eta ordukotz folkloristen artean ezagunak ziren trajeria herrikoiekin ${ }^{4}$. Hots, herrialde hartarik kanpo ere aurkitu nahi izan zituen drama poesia zaharraren hatzak. Haatik, holakorik ezin atxemanez, asmatu zituen teatro horren Lapurdiko aztarnak: Marie de Navarre deitu antzerkia lehenik, eta Santa Jenobebaren kantua ondotik.

Gezurrezko bi aurkikuntza hauek desberdinak ziren: lehenbizikoa eskuizkribu bati zegokion, eta uste izatekoa da horrengatik zail gertatu zitzaiola Micheli iruzurrari gorputz ematea eta luzaz iraunaraztea. Hain zuzen, egiazki eskuizkriburik ez baitzen. Azkenean argitu zen gezurra eta gezur egileak ere aitortu zuen bere bekatua.

Bigarren aurkikuntza ordea, bestelakoa zen: Duvoisinek gazte denboran artzaintsa zahartu baten ahotik bildu zuelako kantu bat baitzen. Neholako euskarri materialik gabeko lekukotasun bat zen, beraz, Duvoisinek berak emana baina Michelen bidez, zeiharka hots, plazaratua. Michelek bere liburuan Duvoisinen

4 - Adibidez, seinalatzekoa da geroago ere Hérellek (1928, 114. or.) Duvoisinen kantuari zegokion drama birtuala ere Sainte Geneviève de Brabant izenburuko pastoralaren aldaera gisa sailkatu zuela. 
lekukotasuna aipu zuzen baten bitartez ekarri baitzuen, badakigu zer gisaz bildu zuen. Alabaina Dubaratek (1907) argitaratu baitzituen Michelek Duvoisini 1855ean igorri bi gutun, eta baita honek egin zizkion erantzunen zirriborroak ere, zirriborro hauetarik batean agertzen da Duvoisinen errana, gero Michelek (1857, 48. or.) bere liburuan hitzez hitz aipatuz baliatuko zuena. Honela ziotsan Duvoisinek Micheli gutun hartan:

J'ai lu avec le plus vif intérêt votre lettre à M. Mérimée [cf. Michel 1854] sur les représentations dramatiques des Basques. J'y ai vu, non sans étonnement, la traduction d'un morceau dont je croyais bien être le seul possesseur, Geneviève dans l'oratoire. Je l'ai recueillie, il y a vingt-cinq ans, de la bouche d'une vieille fille, qui avait dans sa jeunesse joué le rôle de Geneviève, avec un tel feu que sa raison fut ébranlée par les applaudissements de la foule et par le bruit qui s'ensuivit dans tout le pays; ce qui contribuait à l'accroître était l'incognito de l'actrice, qui avait paru teinte et fardée jusqu'aux cheveux. Je l'ai connue grande, maigre et noire ; elle avait les yeux vifs et d'une sévérité extraordinaire, quand elle ne murmurait pas ses chants devant les rochers autour desquels, la quenouille au côté, elle faisait paître quelques misérables brebis. Il me fallut plusieurs mois de patience et de cour pour me faire agréer de la pauvre monomane; encore, n'aije pu obtenir d'elle que la plus faible partie de ce qu'elle savait. Mais j'ai vu cette femme ridée, un genou sur un escabeau, la figure à moitié tournée vers le public devant lequel elle se supposait, les yeux fixés au mur sur une image de Juif errant qui remplaçait le crucifix de l'oratoire; sa poitrine se gonflait comme aux beaux jours de sa jeunesse ; j'ai entendu sa voix chevrotante, vibrante, pénétrante, et jamais je n'oublierai cette scène. (Duvoisinek Michelen 1855/05.27ko gutunari eginikako erantzunaren zirriborroa (datarik gabea); cf. Dubarat 1907, 51. or.)

Uste dut merezi zuela aipu honen osoki ekartzea hona. Arras argiki erakustera ematen du garaiko iruditegian nola ikuskatuak ziren aspaldiko literatura herrikoiaren -kasu honetan poesia dramatikoaren- azken biziarazleak izan zirenak bere biziaren hondar partean. Pintura naif batean bezala kontatua zaigu nola kantatu zizkion artzaintsa gaixo hark Duvoisin gazteari Jenobebaren bertsoak: Judu erratuaren irudi bati kurutzefikari bezala behatzen ziola, ustez behialako entzuleak entzuten zegozkiola, belauna alki baten gainean pausaturik. Horrela kantuz ari izan omen zitzaion Duvoisini boz dardaratsu baina sarkor batekin, bularrak gazte denboran bezala hantzen zitzaizkiolarik...

Geroztik nehor gutik aipatu izan du kantu hau. Egia erran, G\&Uk beren bilduma argitara eman arte nehor ez zen arduratu euskarazko bertsioaren ezagutaraztera ere. Bi helburu izan ditut bertso hauek hemen berriz aipatzerakoan:

- Lehenik, G\&Uk argitaratu bertsioa puntu batean baino gehiagotan zalantzazkoa izanik, testua bere jatorrizko bertsioan eskaintzea.

- Bigarrenik, agerian uztea, kantu honen emaile gisa ekarria den pertsonaia santa Jenobeba izanagatik, nehola ezin lot dakiokeela kantu hau Sainte Geneviève de Brabant izeneko pastoralarekin (hala nola egin baitzuen Hérellek bere katalogoan ; cf. Hérélle 1928) ${ }^{5}$.

5 - XIX. mendeko ikertzaile guziek pentsatu izan dute Zuberoako teatro herrikoia beste herrialdeetan ere (Iparraldekoetan bederen) izan zela aurreko mendeetan, eta testu inguru horretan kokatu behar da iruzurraren alderdi hau. Haatik, engainua hemen agerian emanez ez dugu nehola ere erran nahi ez zela izan XIX. mendea baino lehenago ere Lapurdin euskaraz eginikako teatrorik. Oihenartek Garazin XVI. 
- Hirugarrenik, Duvoisinen iruzurra izan zela azpimarratzea, gisa horretan kantua ezin baitzitekeen, ez testu anonimotzat, ez eta 1780ko testutzat, har (hala nola egin baitzuten Michelek (1857) eta G\&Uk (1991)) .

Hona, beraz, nola agertzen diren bertso hauek Baionako Euskal Erakustokiko 134/05 eskuizkribuan:

§3. Santa Jenobebaren kantuaren jatorriko bertsioa, Baionako Euskal Erakustokiko Duvoisinen 134/05 eskuizkribuaren arabera:

Geneviève à l'oratoire

1.

Nik ez dirot erran

Nik ez dirot penxa

Bibotzean zer dudan

Oi! Neure haxa

5. Doi-doya badoha

airera

zeruetara

Neroni banoba

Harekin batean

10.

15.
Airean

Su handi batek,

Erretzen hari nau;

Baditu hambat gau

Ithotzen nautela

Hasgorapenek,

Nigarrek!

Oi Jaungoiko bandia

zuri dautzut bela,

zure esku eztia
20.

Heda

Diezadazula.

Nik bezala

Sofritzen duenik

othe da?

25.

Lekbu beherenetarik

Gorenetara

Banabila

Zure bilha;

Zeruetara

30.

altchatzen ditut

Begiak;

Ichurtzen ditut

Nigarrezko ithurriak

Zure lebiaz.

Heyen kariaz,

Othoizten zaitut,

Hel zakizkit!

Badakit,

Zugabe

mendean emana izan zen Artzain gorria-ren berri eman zigun, eta funts guti luke Lapurdin ere horrelakorik izan zela besterik gabe edo ezinezkotzat jotzeak. Halere, deusek ez du erakusten izan bide zen teatro horrek XVIII. mendean Zuberoan hedatuko ziren pastoralekin loturarik izan zezakeela. Paradaz balia, aitzineko artikuluan (Oyharçabal 2004) erran bainuen lehenago zenbait autorek, hala nola Lafittek, Oihenarten aipatu pastoral hitza anakronikoki interpretatu zuketela, gaizki aditzera eman nuen Orpustanen (1996, 131. or) kasua ere izan zela. Alderantziz, honek pastoral hitzak Oihenarten aipu hartan une vraie pastorale ou pièce bucolique izendatzen zuela argiki zehaztu zuen, Zuberoako geroztikako tradizioko pastoraletarik argiki bereiziz.

6 - G\&Uk Iparraldeko bertso anonimoak biltzen dituen beren bildumako liburukian, honela diote kantuaren iturria eskaintzen duen erreferentzian (1991,1857. or.): Duv. Santa Jenobeba dramatik ateratako poema, 1780 ingurukoa. Bilduman horretan Duv errreferentziari dagozkion eskuizkribuak Pariseko Nazio Liburutegikoak eta Baionako Euskal Erakustokikoak izan baitaitezke (1991, 1-XXXVII. or.), ezin jakin daiteke iturri zehatza zein izan zuten bildumaren egileek. Micheli egin gutuna 1855ekoa zela jakinik, eta lekukotasuna 25 urte lehenago 'jasoa' izanik, 1830ean edo 'gertatu' zen kondaira hura, Duvoisinek 20 urte zituela. Orduko artzaintsa adinean sartua baitzen aise 19. mendearen hondar partea harrapatzen da emanaldiaren data finkatzerakoan. Alderdi horretarik ez da dudarik G\&Uk aipatu 1780 urtea (ikus 7. oharra) Duvoisinen lekukotasunaren araberakoa dela.

7 - Bai Michelen argitalpenean, bai Duvoisinen eskuizkribuan frantsesa da meta-hizkuntza, eta didaskaliak frantsesez dira. 
40.

$$
\text { Ez dela }
$$

Oi ene jabe

bandien artean

bandi zarena,

zorionik munduan.

45.

Oi zure gana

Eraman nezazu;

Nik ez dut mundupean

Aurkhitzen ahal

Sosegurik.

50.

Banitu bi hegal

Altchatzeko,

Lekbu bautarik

Airatzeko!

Banindohake

55.

60.

65.
Zure aldera,

Aingeruen bake Dohaxura.

Oi Jainko handia,

Zeruko nausia,

Urrikal zaite

Ene abal-gabeari;

Hel zaite

Zure haurrari.

Les Anges

Sosegu har zazu,

Arreba gaichoa!

Zure amodioa

Heldu izan zaiku
Lili eztienaren

Usainaren pare;

70.

Konxola zaite,

Zure bilha gara

Ethorriren.

Ortziriak karraskatzen dueno,

Jainkoaren haxak hura bil arteraino,

75. Har zazu sosegu,

Othoizten zaitugu!

Ez duzu

Guk baino

Gebiago

80.

Elkhar besarkatzeko

Lebiarik!

Eramanen zaitugu

Gurekin

Zeruetarik

85. Jausten garenean manuarekin, Arreba gaichoa,

Zure bozkarioa

Orduan ditake

Handia!

90.

Zeruko loria

Izar argiaren pare

Dirdiratuko da,

Heltzen zarenean

Gure erdian

95.

Parabisura

Jainkoaren aldera

Testu bera da G\&Uk, ortografia gaurkoturik, argitaratu zutena ${ }^{8}$. Aldaketa handienak irakurketa okerrengatik edo errakuntza hutsengatik gertatu dira, nahiz badaitekeen beste zenbaitetan G\&Uk eta nik baliatu eskuidatzietan beretan agertzen ziren".

Irakurketa gehienik trabatzen duten G\&Uren aldaketak edo errakuntzak, Duvoisinen eskuizkribuan zuzen emanak direnak, hauek dira:

8 - Grafia kontuan aldaketa nagusiak hauek dira: Duvoisinen $c h, t c h$ eta $x$ grafiak gaurko eran idazten dituzte G\&Uk, erran nahi baitu $x$, tx eta $t$. Bestalde, herskari aspiratuetako $b$ letra kentzen dute batzuetan (ez beti), baita $l$-ren ondokoa ere. Beste zenbait aldaketa ere badira, hala nola bokalen arteko jota edo ezpainkarien aitzineko sudurkaria grafiatzeko.

9 - Beren liburuan G\&Uk ez dute zehazten zein eskuizkributarik hartu dituzten bertsoak eta beraz ezin izan dut konparatu haiek baliatu eskuidatzia hemen argitaratzen denarekin (cf. 6. oh.). Haatik iduri du iturriak desberdinak izan ditugula, ez baita ikusten zergatik eta zer gisaz bestela, hemen baliatu eskuizkribuko Jaungoiko (17. b.l.) edo Jainko (58, 74, 97. b.l.) hitzak Jangoiko eta Jinko forman agertzen diren G \&Uren argitalpenean. 


\section{7-21. bertso lerroetan}

Duvoisin: Oi Jaungoiko handia / zuri dautzut hela ${ }^{10}$, / zure esku eztia / Heda / Diezadazula.

G\&U: Oi, Jangoiko handia! / Zuri dautzut heda, / Zuri esan eztia / Heda / Diezadazula,

\section{5. bertso lerroan}

\section{Duvoisin: beyen kariaz}

\section{G\&U : Heren kariaz}

38-44 bertso lerroetan

Duvoisin: Badakit / Zugabe / Ez dela / Oi ene jabe / handien artean / handi zarena, / zorionik munduan.

G\&U: Badakit / Zugabe / Ez dela / Abiatzeko ${ }^{11}$, / Oi ene jabe!, / Handien artean / Handi zarena, / Zorionik munduan.

\section{8. bertso lerroan}

\section{Duvoisin: Guk baino}

\section{G\&U : Gu baino}

Beste batzuetan ez da argi irakurketa oker baten ondorioz edo eskuizkribuetako kanbiamenduengatik aurkitzen diren aldaerak. Adibidez, 12. bertso lerroan bi aldaera hauek ditugu:

\section{2. bertso lerroan ${ }^{12}$}

Duvoisin: Su handi batek, / Erretzen hari nau

G\&U : Su bandi batek / erretzen bainau

Azken bertso lerroan ere bi aldaera dira ${ }^{13}$ :

96. bertso lerroan

\section{Duvoisin : Jainkoaren aldera}

\section{G\&U : Jinkoaren aldarera}

Duvoisinen Baionako Erakustokiko 134/05 eskuizkribuak kantuaren frantsesezko itzulpenaren testua ere baitakar, ohargarria da itzulpen hori ez darraiola Michelek (1857, 47-48. or.) argitaratu zuenari. Ez dakigu Michelek publikatu zuen itzulpen hura, berak egin (edo eginarazi) zuen ala baliatu zuen iturrian ere agertzen zen.

10 - Hela hitzaren irakurketa segur-segura da. DGV-OEHak (6-531. or.) ere Duvoisinen Liburu Ederra-tik atera beste adibide bat ematen du, honen irudikoa: Oi Jauna, urrikalmendu guzietako itburburua, entzun ezazu nere hela.

11 - Hitz bat (abiatzeko) horrela sartuz, bertso multzo guzia aldatzen da. Errakuntza ote da? Dena den, ustegabekoa litzateke Duvoisinen jatorrizko eskuizkribuan horrela izatea. Itzulpenak ere ez du dudarik uzten: Je sais, ô mon Maître, qui étes grand au-dessus des grands, je sais que sans vous il n'est pas de bonbeur sur la terre.

12 - Erretzen hari nau forma markatua izanagatik, ez da, noski, hutsa. Hari forma $b$-duna lapurtera klasikotik heldu da (ari era berriagoa izanik), eta gerta zitekeen orduan ere Iparraldeko zenbait euskalkitan modu horretan, erran nahi baitu modu iragangorrean, erabiltzea ari izan lokuzioa (haren perpaus osagarriko aditza bera ere iragankorra izanik, noski). Ikus, adibidez, Laphitzen adibide hau, arras itxura berekoa dena: Zorionaren bizitasunak ithotzen ari nau (Bi saindu beskualdunen bizia, 189. or.) 13 - Guk baliatu eskuizkribuan aldera-ren irakurketak ez du zalantzarik sortzen, Michelek (1857, 49. or.) eman itzulpenak bezala: quand vous arriverez - au milieu de nous, - au paradis, - auprès de Dieu. Ohar, halere, Duvoisinek eman frantsesezko bertsioa bestela itzulia dela, autel hitza erabiliz (pluralean haatik): quand vous parviendrez au milieu de nous dans le sanctuaire de Dieu, aux pieds de ses autels. 
Dena den, ez da dudarik Michelen itzulpena euskarazko testuari biziki hurbilagotik jarraikitzen zitzaiola, estiloa hobeki zaindurik, hemen eskaintzen dugun eskuzkribua baino.

$\S 4$. Frantseserako itzulpena (Duvoisinek bere eskuizkribuan euskarazko testuaren ondoan emana):

Je ne sais, ne puis dire ce qui agite mon cour. Mon haleine s'échappe avec peine dans les airs, vers les cieux, et je crois m'envoler avec elle.

Un feu brûlant me dévore; depuis combien de nuits les soupirs et les larmes ne me suffoquent-ils pas?

Dieu puissant, j'élève vers vous ma voix; ob! Je vous en supplie, tendez-moi une main secourable.

Est-il quelqu'un qui souffre comme moi? Des lieux les plus bas je cours jusqu'aux plus élevés; je vous cherche, mon Dieu! Je lève les yeux au ciel et le désir de vous posséder me fait verser des torrents de larmes. En considération de ces larmes, venez, je vous prie, venez, à mon secours!

Je sais, ô mon Maître, qui êtes grand au-dessus des grands, je sais que sans vous $i l$ n'est pas de bonheur sur la terre. Ob! retirez-moi vers vous; je ne saurais au milieu du monde trouver aucun repos.

Si j'avais deux ailes pour prendre mon essor, m'élancer de ces bas lieux! Je me précipiterais dans votre sein au milieu de la bienheureuse paix des anges.

Ob! Dieu puissant, souverain maître du ciel, prenez pitié de ma faiblesse, venez en aide à votre enfant.

\section{Les anges}

Consolez-vous, sœur bien aimée, votre amour est monté jusqu'à nous, semblable au parfum de la plus douce des fleurs; consolez-vous, nous viendrons vous chercher.

Prenez patience, nous vous en prions, jusqu'à l'heure qu'il plaira au seigneur d'éteindre de son souffle l'orage qui gronde encore.

Votre désir de nous embrasser n'est pas plus ardent que celui qui nous anime.

Dès que l'ordre du Tout Puissant nous fera descendre de notre demeure, nous viendrons vous prendre et vous emporter au céleste séjour. Ob! alors, bien aimée, votre joie sera immense. Et la gloire des cieux rayonnera comme les étoiles quand vous parviendrez au milieu de nous dans le sanctuaire de Dieu, aux pieds de ses autels.

Testu hori euskarazkoarekin konparatzen delarik, ikus daiteke Duvoisinek aski libroki itzultzen duela, hitzez-hitz segitu gabe. Alderantziz, Michelek (1857, 47-48. or.) eskaini bertsioan anitzez hurbilagotik segitzen zen euskarazko testua (estilistikari kasu handirik egin gabe). Konpara adibidez bertso hauek:

Euskarazko testua: Sosegu har zazu / Arreba gaichoa! / Zure amodioa / Heldu izan zaiku / Lili eztienaren / Usainaren pare; / Konxola zaite, / Zure bilha gara / Ethorriren. 
Michel: Consolez-vous, / pauvre chère sour. / Votre amour / nous est venu, / de la plus douce fleur / pareil au parfum. / Consolez-vous. / pour vous chercher / nous arrivons.

Duvoisin: Consolez-vous, sœur bien aimée, votre amour est monté jusqu'à nous, semblable au parfum de la plus douce des fleurs; consolez-vous, nous viendrons vous chercher.

\section{Bibliografia}

— Bidart, P. 2001. La singularité basque, Presses Universitaires de France, Paris.

- Bladé, J-F. 1866. Dissertation sur les chants hérö̈ques des Basques, A. Franck, Paris.

- Bladé, J-F. 1869. Études sur l'origine des Basques, Paris, reprint SlatkineMegariotis, Genève, 1976.

- DGV-OEH. 1987-2004. Diccionario General Vasco, 16 liburuki, Euskaltzaindia, Bilbao.

— Dubarat, V. 1907. 'Lettres adressées au capitaine Duvoisin (I)', RIEV, 49-55.

- Duvoisin, J. 1841a. 'La poésie dramatique des Basques', Album Pyrénéen, martxoa, Paue, 90-102.

— Duvoisin, J. 1841b. 'Comédie des Basques', Album Pyrénéen, maiatza, Paue, 207215.

- Garzia, J. eta Urkizu, P. 1991. Bertsolaritzaren Historia. Lapurdi, Baxanabarre eta Zuberoako bertso eta kantak, 2 liburuki, Etor, Donostia.

- Hérelle, G. 1926. Les pastorales à sujet tragique considérées littérairement, Champion, Paris.

— Hérelle, G. 1928. Le répertoire du théâtre tragique, Catalogue analytique, Société des Sciences, Lettres, Arts \& Etudes Régionales de Bayonne, Baiona.

— Juaristi, J. 1987. El lineaje de Aïtor, Taurus, Madrid.

— Léon, A.. 1909. Une pastorale basque, Hélène de Constantinople, Étude bistorique et critique, Honoré Champion, Paris.

- Michel, (dit Francisque-Michel). 1854. 'Lettre à M.P. Mérimée sur les représentations dramatiques en Pays Basque', in Le Messager de Bayonne, abenduaren 14koa.

- Michel, (dit Francisque-Michel). 1857. Le Pays Basque, sa population, sa langue, ses moeurs, bigarren argitalpena 1981, Elkar, Baiona.

— Orpustan, J-B. 1996. Précis d'histoire littéraire basque, Izpegi, Baigorri.

- Oyharçabal, B. 2004. 'Place de sainte Elisabeth de Portugal (1750) dans l'histoire des tragédies traditionnelles en langue basque', Lapurdum, Baiona, 180-214. 
- Vinson, J. 1884. Notice bibliographique sur le folklore du Pays Basque, Maisonneuve, Paris.

Webster, W. 1899. 'Les pastorales basques', in La tradition au Pays Basque, artikulu bilduma, bigarren argitalpena 1994, 243-261, Elkar, Baiona. 